\title{
THE EFFECT OF STAIN RATE ON MECHANICAL PROPERTIES AND RETAINED AUSTENITE STABILITY IN C-Mn-Si-AI-Nb STEEL
}

\author{
Ludmila KUČEROVÁ, Štěpán JENÍČEK, Jan MACH, Andrea KADLECOVÁ \\ UWB - University of West Bohemia in Pilsen, Pilsen, Czech Republic, EU \\ skal@rti.zcu.cz, jeniceks@rti.zcu.cz, machj@rti.zcu.cz, jandovaa@rti.zcu.cz
}

https://doi.org/10.37904/metal.2019.856

\begin{abstract}
Low carbon low alloyed TRIP steel with partial substitution of silicon by aluminium was thermo-mechanically treated to obtain a multiphase microstructure typical for TRIP steels. The processing consisted of soaking at $900{ }^{\circ} \mathrm{C}$ and two compressive deformations applied during the cooling to the isothermal hold temperature of $425{ }^{\circ} \mathrm{C}$. The microstructure was predominantly bainitic with about $17 \%$ of retained austenite and little proeutectoid ferrite. Bainite consisted of the mixture of bainitic ferrite and retained austenite laths. The samples underwent tensile test with five different strain rates, 0.003, 0.3, 1, 10, $100 \mathrm{~s}^{-1}$. Mechanical properties show some dependency on strain rate, tensile strengths of $832-925 \mathrm{MPa}$ were achieved together with total elongation of $30-38 \%$. Significantly higher strain rates of 380,470 and $520 \mathrm{~s}^{-1}$ were produced by impact test with various initial positions of the pendulum $\left(90^{\circ}, 120^{\circ}, 150^{\circ}\right)$. In these cases, only the impact energy was evaluated, showing the increasing values with increasing deformation rate. The effect of increasing strain rate on the stability of retained austenite was also evaluated by the means of X-ray diffraction phase analyses. The microstructure after the straining was documented by scanning electron microscopy, as well as fracture surfaces.
\end{abstract}

Keywords: TRIP steel, strain rate, retained austenite, multiphase microstructure, aluminum

\section{INTRODUCTION}

Advanced high strength steels (AHSS) belong to materials frequently used in an automotive industry. This defines requirements on their mechanical and technological properties. Besides excellent formability, good weldability, high strength and cost effective alloying design and processing technology, the steels should also contribute to a high passenger safety in the case of an accident. For this particular purpose, AHSS with transformation induced plasticity (TRIP) effect present a suitable candidate [1,2]. Several grades of AHSS, which are using a beneficial effect of strain-induced transformation of a controlled fraction of metastable retained austenite to martensite, have been developed in last two decades [3,4]. The most important new grades are low alloyed multiphase TRIP steels, martensitic steels with retained austenite processed by quenching and partitioning process and medium-to-high manganese TRIP steels. Transformation of retained austenite tends to consume relatively large amount of crash energy, particularly in TRIP steels, and thus decrease the danger for the passengers [5,6]. This ability depends on high strain rate behavior of retained austenite. To this type of steels belongs also low alloyed low carbon TRIP steels with a very simple alloying concept based on $0.2-0.4 \% \mathrm{C}$ and between $1-2 \%$ of manganese and silicon. Higher silicon contents turned out to be unsuitable for application in automotive industry, due to oxide formation, which deteriorates surface quality and causes poor galvanization performance. Therefore, partial or full substitution of silicon by aluminum has been introduced [5]. Aluminum has similar effect on solid solution strengthening and carbide precipitation hindering as silicon. The impact of aluminum is however smaller than the same amount of silicon have and full substitution would result in decrease of tensile strength of the steel [7]. This is the reason why partial substitution was used in this work. Several papers has been published on the effect of strain rate on mechanical properties of low alloyed TRIP steels containing around $2 \%$ of silicon and no aluminum [8]. The effect of strain rate on deformation behavior of aluminum alloyed TRIP steels has been on the other hand recently studied 
mainly for medium or high manganese steels of the third generation, where the interplay of TRIP and TWIP (transformation twinning plasticity) effects can be expected [9-11]. Deformation behavior of low manganese and medium manganese steels alloyed by aluminum could however differ significantly. For example, negative strain rate sensitivity (SRS) was reported for medium manganese TRIP steels [12], which is generally not observed in conventional low alloyed TRIP steels [13,14]. While quasi-static mechanical properties of low alloyed TRIP steels with aluminum are often studied [15], relatively few works concentrated on high strain rate behavior [14] of these materials. This works aims to characterize the effect of strain rate on mechanical properties and retained austenite stability of $0.2 \mathrm{C}-1.5 \mathrm{Mn}-0.6 \mathrm{Si}-1.4 \mathrm{Al}-0.06 \mathrm{Nb}$ TRIP steel processed by thermomechanical treatment.

\section{EXPERIMENTAL PROGRAM}

Low alloyed high strength steel with partial substitution of silicon by aluminium was used for this work (Table 1). The steel was alloyed by manganese which helps to stabilize retained austenite to room temperature. Silicon was originally used in this type of steel to hinder carbides precipitation during annealing holds and thus preserve more carbon in solid solution. In this indirect way, the carbon content in austenite was increased and better stabilization of retained austenite was obtained. This effect is in the used steel achieved mainly by aluminium, which at the same time increases solid solution strengthening. Micro-addition of niobium was often suggested for TRIP steels to refine the final microstructure and increase retained austenite volume fraction. However, in this work, niobium is used for the technological reason, as it was demonstrated to shift pearlite formation to longer times for low alloyed TRIP steel [15].

Table 1 Chemical composition of used steel in wt.\%.

\begin{tabular}{|c|c|c|c|c|}
\hline $\mathbf{C}$ & $\mathbf{M n}$ & $\mathbf{S i}$ & $\mathbf{A l}$ & $\mathbf{N b}$ \\
\hline 0.2 & 1.6 & 0.6 & 1.4 & 0.06 \\
\hline
\end{tabular}

Two step thermo-mechanical treatments (Figure 1a) typical for the processing of TRIP steels was applied to CMnAINb steel. The treatment consisted of $100 \mathrm{~s}$ hold at $900{ }^{\circ} \mathrm{C}$, cooling by $30^{\circ} \mathrm{C} / \mathrm{s}$ to $425^{\circ} \mathrm{C}$ and a second hold of $600 \mathrm{~s}$ at the temperature of $425^{\circ} \mathrm{C}$. Two compressive deformations were carried out during the processing, the first one at the end of a soaking hold at $900{ }^{\circ} \mathrm{C}$, the second one during the cooling at the temperature of $720^{\circ} \mathrm{C}$. All the samples were heat treated in the same way, using thermo-mechanical simulator. Mechanical testing was carried out at the thermo-mechanical simulator at room temperature, using deformation rates from 0.003 to $100 \mathrm{~s}^{-1}$. To achieve higher deformation rates of $380-520 \mathrm{~s}^{-1}$, the equipment for Sharpy impact test was used with three different initial positions of the pendulum $\left(90^{\circ}, 120^{\circ}, 150^{\circ}\right)$. The same geometry of testing specimens was used for both methods (Figure 1b).

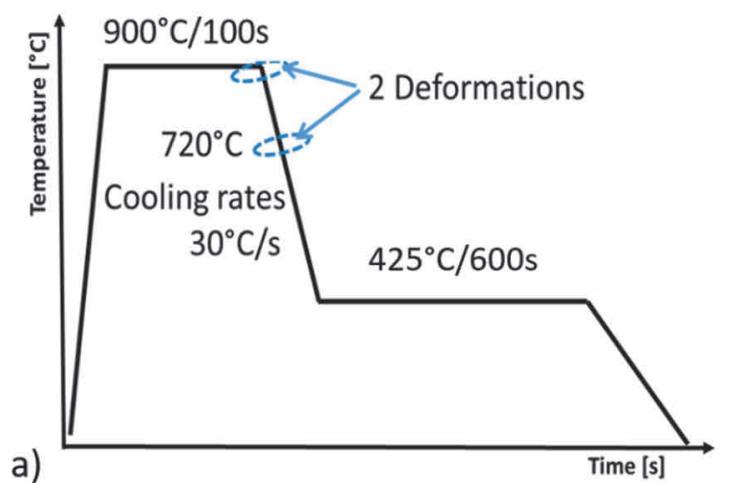

Figure 1 a) Scheme of thermo-mechanical treatment, b) Geometry of the sample for mechanical testing 
Microstructure analysis and fractography were carried out by light microscopy and scanning electron microscopy (SEM), using VEGA SEM with tungsten cathode and EVO 25 with $\mathrm{LaB}_{6}$ cathode. Metallographic sections were prepared along longitudinal axe of the tensile samples to determine retained austenite volume fraction in the necking area. The volume fraction of the retained austenite was determined by X-ray diffraction phase analysis using an AXS Bruker D8 Discover automatic powder diffractometer with a HI-STAR detector and Co lamp ( $\lambda K \alpha=0.1790307 \mathrm{~nm}$ ). The measurement was carried out in the central part of the samples and spectra were taken in the range of $2 \vartheta$ from $25^{\circ}$ to $110^{\circ}$. The integrated intensities of (200) ferrite peak and (111), (002) and (022) austenite peaks were used for evaluation. Carbon content in retained austenite was calculated considering the effect of alloying elements according to [7]: $a=3.572+0.0012 \mathrm{Mn}-0.00157 \mathrm{Si}+$ $0.0056 \mathrm{Al}+0.033 \mathrm{C}$, where $\mathrm{a}$ is the lattice parameter (in $\mathrm{nm}$ ) of the retained austenite calculated from the three austenite peaks measured by $\mathrm{X}$-ray diffraction phase analysis. The amounts of alloying elements are given in weight percent.

\section{RESULTS AND DISCUSSIONS}

After two step heat treatment, the microstructure of the steel was bainitic-ferritic with $17 \%$ of retained austenite (Figure 2). The microstructure was predominantly bainitic with about $11 \%$ of very fine proeutectoid ferrite. Bainitic areas were relatively evenly distributed and were mainly of lath or acicular type. Carbon content in the retained austenite was $1.53 \%$. First of all, quasi static tensile test was performed with strain rate of $0.003 \mathrm{~s}^{-1}$ so that reference mechanical properties would be obtained. Following mechanical properties were achieved: yield strength $560 \mathrm{MPa}$, tensile strength $832 \mathrm{MPa}$ and total ductility $38 \%$. After tensile test, $5.8 \%$ of retained austenite was still found in the proximity of fracture surface, where most intensive plastic deformation occurred. This retained austenite contained $1.34 \%$ of carbon.

A set of tensile tests with increasing deformation rates was further performed. Table 2 demonstrates that with the exception of strain rate $1 \mathrm{~s}^{-1}$, tensile strength was higher than the one obtained at quasi-static loading. Increased strain rates of $10 \mathrm{~s}^{-1}$ and $100 \mathrm{~s}^{-1}$ resulted in a significant drop of yield strength to around $370 \mathrm{MPa}$. Very small changes in total elongation values were observed with elongation decreasing with increasing strain rate. There was a more significant drop of total elongation between quasi static loading with strain rate of $0.003 \mathrm{~s}^{-1}$ and the following strain rate of $0.3 \mathrm{~s}^{-1}$.

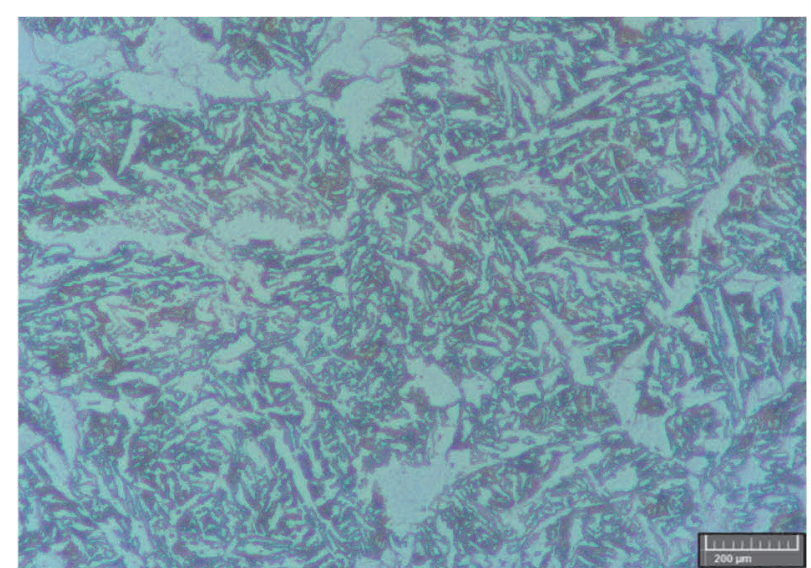

a)

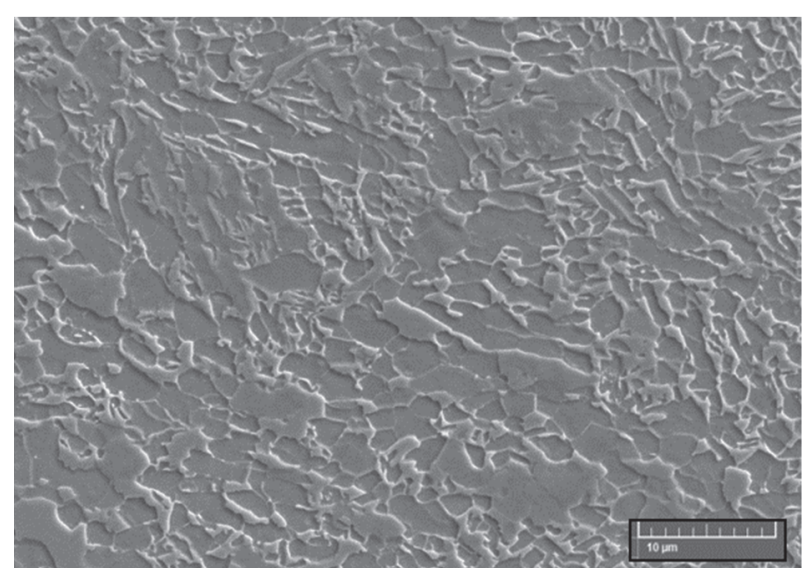

b)

Figure 2 Bainitic-ferritic microstructure with retained austenite obtained by thermo-mechanical treatment

The development of total elongation with increasing strain rate corresponds to earlier findings within the same strain rates $[6,8,9]$. Decreasing elongation is contributed to deformation localisation, as dislocation slide is difficult at higher strain rates due to the large multiplication of dislocations and short deformation times [8]. 
On the other hand, obtained ultimate tensile strengths are not in exact agreement with previous works on dynamic loading of TRIP steels $[6,8,9]$. It was generally suggested, that tensile strength increases significantly with increasing strain rate. However, the proposed mechanism of this strengthening was connected with strengthening of ferrite matrix due to the hindrance of dislocation sliding resulting from large multiplication of dislocations around hard phases and short deformation times [8]. Ferrite commonly formed $40-60 \%$ of the microstructure of those CMnSi TRIP steels and therefore this effect was significant. However, in the case of presented CMnAINb steel, the microstructure was predominately bainitic and the strengthening effect of proeutectoid or polygonal ferrite wouldn't play a crucial role in its mechanical properties.

Three highest strain rates of $380 \mathrm{~s}^{-1}, 470 \mathrm{~s}^{-1}$ and $520 \mathrm{~s}^{-1}$ were achieved by impact loading, using tree different initial positions (heights) of the pendulum. Impact energy needed to break the samples increased markedly from $240 \mathrm{~J}$ to $449 \mathrm{~J}$ with strain rate increasing from $380 \mathrm{~s}^{-1}$ to $520 \mathrm{~s}^{-1}$.

Volume fraction of retained austenite was in the range of $4.4 \%-5.8 \%$ with carbon contents varying between 1.29 and $1.69 \%$. Higher carbon content in the retained austenite generally means higher stability of this austenite against strain induced transformation [7]. Obtained range of carbon contents might seem very high with respect to the total carbon content in the steel, but it is in fact quite typical for carbon content in retained austenite of TRIP steel to surpass $1 \%$. This is caused by carbon enrichment of remaining austenite during the bainitic transformation, which occurs in a second annealing step of heat treatment of TRI steel [1,2], in the case of this work at $425^{\circ} \mathrm{C}$.

The highest amount of the retained austenite was found in the sample after quasi static loading, while the highest carbon content was calculated for the sample with the highest strain rate. However, there was no visible relationship between strain rate, retained austenite volume fraction and retained austenite carbon content. It should be also noted, that the differences in retained austenite volume fractions were quite low, considering the accuracy of evaluation method and heterogeneity of the microstructure, the amount of transformed retained austenite at necking zone under different strain rate could be considered the same.

Table 2 Tensile properties obtained at various strain rates, impact energy $(K)$, volume fraction of retained austenite (RA), lattice parameter (a) and carbon content in retained austenite after fracture (C)

\begin{tabular}{|c|c|c|c|c|c|c|c|}
\hline $\begin{array}{c}\text { Deformation } \\
\text { rate s-1 }\end{array}$ & $\begin{array}{c}\mathrm{Re} \\
{[\mathrm{MPa}]}\end{array}$ & $\begin{array}{c}\mathrm{Rm} \\
{[\mathrm{MPa}]}\end{array}$ & $\begin{array}{c}\mathrm{A} \\
{[\%]}\end{array}$ & $\begin{array}{c}\mathrm{K} \\
{[\mathrm{J}]}\end{array}$ & $\begin{array}{c}\mathrm{RA} \\
{[\%]}\end{array}$ & $\begin{array}{c}\mathrm{a} \\
{[\mathrm{nm}]}\end{array}$ & $\begin{array}{c}\mathrm{C} \\
{[\mathrm{wt} . \%]}\end{array}$ \\
\hline 0.003 & $560 \pm 13$ & $832 \pm 2$ & $38 \pm 1$ & - & 5.8 & 0.36208 & 1.34 \\
\hline 0.3 & $629 \pm 11$ & $94 \pm 2$ & $34 \pm 1$ & - & 4.8 & 0.36215 & 1.36 \\
\hline 1 & $648 \pm 6$ & $835 \pm 2$ & $33 \pm 0$ & - & 5 & 0.36250 & 1.47 \\
\hline 10 & $362 \pm 12$ & $895 \pm 2$ & $31 \pm 0$ & - & 5.2 & 0.36191 & 1.29 \\
\hline 100 & $385 \pm 10$ & $925 \pm 1$ & $32 \pm 1$ & - & 4.4 & 0.36247 & 1.46 \\
\hline 380 & - & - & - & $240 \pm 0$ & 4.6 & 0.36243 & 1.44 \\
\hline 470 & - & - & - & $360 \pm 0$ & 5.5 & 0.36255 & 1.48 \\
\hline 520 & - & - & - & $449 \pm 0$ & 4.9 & 0.36296 & 1.61 \\
\hline
\end{tabular}

Fracture surfaces of all samples were examined in detail using scanning electron microscopy and the overview of fracture surfaces obtained by three representative strain rates is provided in Figure 3. It can be observed that all fracture surfaces show similar ductile morphology, both in macro and micro views. Fracture surfaces were in all cases of "cup and cone" type with dimple morphology. The central parts (bottom of the cup) cover similar areas and are surrounded by similar sized shear lips. It can be however seen that the sides of many dimples are markedly stretched in fracture surface (Figure 3f) produced by the highest strain rate of $520 \mathrm{~s}^{-1}$ and also several very coarse dimples were found in the central part of fracture surface (Figure 3c). 


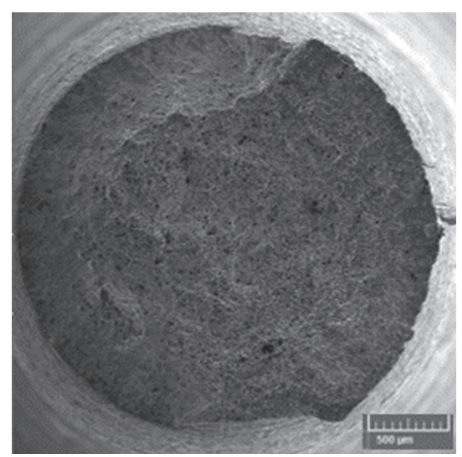

a)

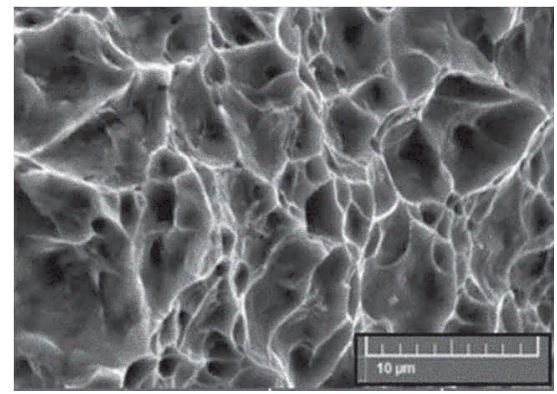

d)

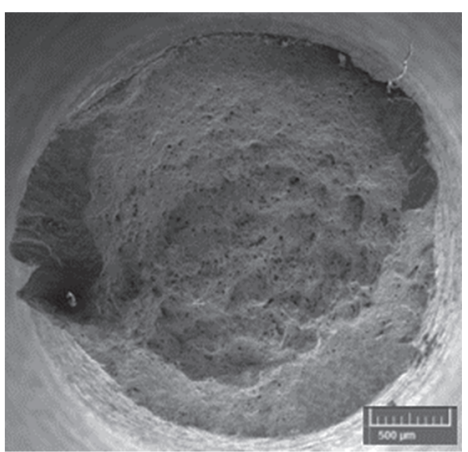

b)

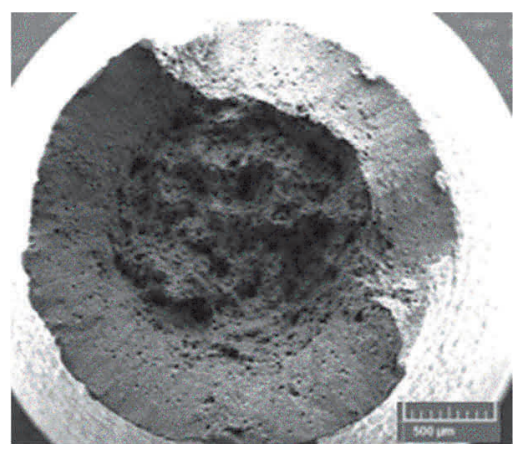

c)

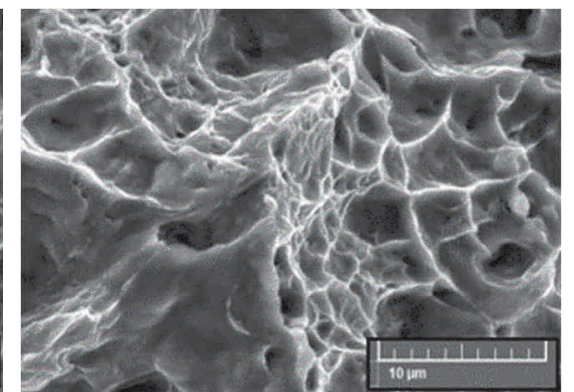

e)

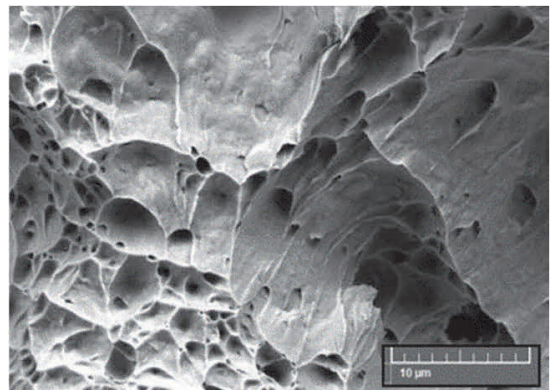

f)

Figure 3 Fracture surfaces a)-c) macro view, d)-f) details from the central part. Sample with: strain rate 0.3 $\mathrm{s}^{-1}$ a) d), strain rate $10 \mathrm{~s}^{-1}$ b) e), strain rate $520 \mathrm{~s}^{-1} \mathrm{c}$ ) f)

\section{CONCLUSION}

The effect of various strain rates in the interval of $0,003 \mathrm{~s}^{-1}$ to $520 \mathrm{~s}^{-1}$ was tested for or low carbon low alloyed CMnAINb steel. Deformation rates up to $100 \mathrm{~s}^{-1}$ were applied by thermo-mechanical simulator during tensile test, the highest deformation rates were achieved by impact testing. With increasing strain rates, the total elongation of tensile samples slightly decreased, however the most significant drop occurred with the transition from quasi static loading to the strain rate of $0.3 \mathrm{~s}-1$. This is in agreement with previous works on high strain rate behaviour of TRIP steels. The trend in ultimate tensile strength doesn't correspond to previous published results, which might be caused by a bainite-based microstructure of present CMnAINb steel, while previous reports were mainly concerned with microstructures possessing ferrite matrix. It was the strengthening of this ferrite that is believed to result in significant increase of ultimate tensile strength with increasing strain rates. Further investigation of the mechanism of response of predominantly bainitic TRIP steel to high strain rate loading will be therefore needed to explain tensile strength of CMnAINb steel. The highest amount of the retained austenite was found in the sample after quasi static loading, while the highest carbon content was calculated for the sample with the highest strain rate. However, there was no visible relationship between strain rate, retained austenite volume fraction and retained austenite carbon content and due to small variations in retained austenite volume fraction; the amount of transformed retained austenite at necking zone under different strain rate could be considered the same.

\section{ACKNOWLEDGEMENTS}

The present contribution has been prepared with the support of the student grant competition of University of West Bohemia in Pilsen, SGS 2018-045. 


\section{REFERENCES}

[1] BHATTACHARYYA, T. Development and Characterisation of C-Mn-Al-Si-Nb TRIP Aided Steel. Materials Science and Engineering A. 2011. vol. 528, no. 6, pp. 2394-2400.

[2] KUČEROVÁ, L. The Effect of Two-Step Heat Treatment Parameters on Microstructure and Mechanical Properties of 42SiMn Steel. Metals. 2017. vol. 7, no. 12, pp. 1-14.

[3] LI, L. Effect of Aluminum and Silicon on Transformation Induced Plasticity of the TRIP Steel. Journal of Materials Science \& Technology. 2004. vol. 20, no. 2, pp. 135-38.

[4] KUČEROVÁ, L., AIŠMAN, D., JIRKOVÁ, H., MAŠEK, B. and HAUSEROVÁ, D. Optimization of q-p process parameters with regard to final microstructures and properties. In Annals of DAAAM and Proceedings of the International DAAAM Symposium, 2009, pp. 1035-1036.

[5] BHATTACHARYYA, T. An Assessment on Coatability of Transformation Induced Plasticity (TRIP)-Aided Steel. Surface and Coatings Technology. 2013. vol. 235, pp. 226-34.

[6] CURTZE, S. KUOKKALA, V.T., HOKKA, M. and PEURA, P. Deformation behavior of TRIP and DP steels in tension at different temperatures over a wide ranges of strain rates. Mater. Sci. Eng. 2009. vol. 507, pp. 124-131.

[7] CHIANG, J. BOYD, J.D.and PILKEY, A.K. Effect of microstructure on retained austenite stability and tensile behaviour in an aluminum-alloyed TRIP steel. Mater. Sci. Eng. A. 2015. vol. 638, pp. 132-142.

[8] ZHONGPING, H., YANLIN, H., YUANTAO, L., QIHAO, W., YI, G.and LIN, L. Effect of strain rate on deformation behavior of TRIP steels. Journal of Materials Processing Technology. 2012. vol. 212, pp 2141-2147.

[9] XIE, P., WU, C.L. and CHEN, Y. A nanotwinned surface layer generated by high strain-rate deformation in a TRIP steel. Materials and Design. 2015, vol. 80, pp. 144-151.

[10] LI, K., INJETI, V.S.Y. and MISRA, R.D.K. On the strain rate sensitivity of aluminium-containing transformationinduced plasticity steels: Interplay between TRIP and TWIP effects. Material Science and Engineering A. 2018. vol. 711, pp. 515-523.

[11] OZTURK, F. POLAT, A., TOROS, S. and PICU, R.C. Strain hardening and strain rate sensitivity behaviors of advanced high strength steels. J. Iron Steel Res. Int. 2013. vol. 20, pp. 68-74.

[12] CALLAHAN, M., PERLADE, A. and SCHMITT, J. H. Interactions of negative strain rate sensitivity, martensite transformation and dynamic strain aging in $3^{\text {rd }}$ generation advanced high-strength steels. Materials Science and Engineering A. 2019. vol. 754, pp. 140-151.

[13] XIA, P. VERCRUYSSE, F., PETROV, R., SABIROV, I., RODRIGUEZ, M.C.and VERLEYSEN, P. High strain rate tensile behavior of a quenching and partitioning (QP) Fe0.25C-1.5Si-3.0Mn steel. Materials Science and Engineering A. 2019, vol. 745, pp. 53-62.

[14] SLYCKEN, J.V., VERLEYSEN, P. and DEGRIECK, J. Dynamic response of aluminium containing TRIP steel and its constituent phases. Materials Science and Engineering A. 2007. vol. 460-461, pp. 516-524.

[15] KUČEROVÁ, L., OPATOVÁ, K., KÁŇA, J. and JIRKOVÁ, H. High verstatility of niobium alloyed AHSS. Archives of Metallurgy and Materials. 2017. vol. 62, no. 3, pp. 1485-1491. 